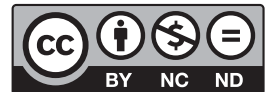

Estudos Teológicos foi licenciado com uma Licença Creative Commons Atribuição - NãoComercial - SemDerivados 3.0 Não Adaptada

http://dx.doi.org/10.22351/et.v60i1.3927

\title{
A RELAÇÃo ENTRE DIGNIDAdE HUMANA E NÃO VIOLÊNCIA NO MAGISTÉRIO PONTIFÍCIO ${ }^{1}$ \\ The relationship between human dignity and nonviolence in papal magisterium
}

\section{Felipe Sérgio Koller ${ }^{2}$ Suzana Regina Moreira ${ }^{3}$ Jefferson Zeferino ${ }^{4}$}

Resumo: O presente artigo apresenta a correlação entre não violência e dignidade humana a partir de um mapeamento do termo "não violência" nos textos do magistério dos papas. Originada no jainismo, a ideia da não violência foi defendida no último século sobretudo por Mahatma Gandhi e Martin Luther King Jr. Foi absorvida pelos papas do pós-Concílio Vaticano II a partir do diálogo inter-religioso e intercultural, embora seja tida também por eles como inerente à fé cristã. Paulo VI foi o primeiro papa a utilizar a expressão "não violência" em seus textos, sendo que o primeiro uso remonta a 1964. João Paulo II destacou que o fundamento da não violência é o reconhecimento da dignidade humana, no que foi seguido por seus sucessores, Bento XVI e Francisco, cada um a seu próprio modo. Como resultado, nota-se a força de sentido da não violência em sua possibilidade de contribuição a uma ética pública, como elemento de destaque no diálogo inter-religioso e como resistência às formas religiosas de expressão que se caracterizam justamente pelo ódio e pela violência. Palavras-chave: Teologia pública. Magistério pontifício. Não violência. Dignidade humana. Diálogo inter-religioso.

Abstract: The following article presents the correlation between nonviolence and human dignity, using as a starting point the term "nonviolence" as mentioned in texts from the magisterium of the popes. Originated in Jainism, the idea of nonviolence was defended in the last century especially by Mahatma Gandhi and Martin Luther King Jr. It was absorbed by the popes after the Second Vatican Council stemming from interreligious and intercultural dialogue, although considered by them as inherent to the

$1 \mathrm{O}$ artigo foi recebido em $1^{\circ}$ de março de 2020 e aprovado em 13 de abril de 2020 com base nas avaliações dos pareceristas ad hoc.

2 Mestre e doutorando em Teologia. Pontifícia Universidade Católica do Paraná (PUCPR). Bolsista CAPES. E-mail: felipesergiokoller@gmail.com

3 Mestranda em Teologia. Pontifícia Universidade Católica do Rio de Janeiro (PUC-Rio). Bolsista CAPES. E-mail: suzaregi@gmail.com

4 Doutor em Teologia. Pontifícia Universidade Católica do Paraná (PUCPR). Bolsista PNPD/CAPES. E-mail: jefferson.zeferino@pucpr.edu.br 
Christian faith. Paul VI was the first pope to use the expression "nonviolence" in his texts, the first one dating back to 1964. John Paul II highlighted that the foundation of nonviolence is the recognition of human dignity, which later was reaffirmed by his successors, Benedict XVI and Francis, each in their own way. As a result, the strength of the meaning of human dignity is observed in its potential of contributing to public ethics, as a remarkable element in interreligious dialogue and resistance to religious forms of expression that are characterized precisely by hate and violence.

Keywords: Public Theology. Papal magisterium. Nonviolence. Human dignity. Interreligious dialogue.

\section{Considerações iniciais}

As religiões são fonte de violência. Essa ressalva precisa estar posta. Não raro são as religiões que servem de motivo para discursos de ódio, preconceito, terrorismo, intolerância religiosa, segregação racial, guerras. Entretanto, são também as religiões grandes promotoras de respeito à dignidade humana e da paz. ${ }^{5}$ Essa ambiguidade é recorrente diante de formas distintas de expressão religiosa no espaço público. Perspectivas de teor fundamentalista tendem ao fechamento à alteridade, pois aquilo que é distinto é caracterizado como uma ameaça à hegemonia. ${ }^{6}$ Por outro lado, tendências teológicas abertas a encontros interculturais compreendem a alteridade e a diversidade como um dom. ${ }^{7}$

A segunda perspectiva pode ser mais bem assumida diante da tarefa de reconhecimento, defesa e promoção dos direitos humanos. Em virtude disso, o presente artigo se ocupa da relação entre dignidade humana e não violência passando por um recorrido histórico e conceitual, bem como a partir de uma análise dessa temática no magistério pontifício. Compreende-se, portanto, que há uma força de sentido pública em tradições religiosas que pode ajudar a pensar a vida humana na atualidade, fomentando uma existência de abertura e acolhimento da alteridade.

\section{Não violência: aspectos históricos e conceituais}

O conceito de não violência está relacionado com o pacifismo. Enquanto o pacifismo tem sido descrito de modo estrito como oposição à guerra, a não violência está relacionada à questão ética, podendo, inclusive, designar um método ou prática.

5 Essa ambiguidade é bem tematizada em SINNER, Rudolf von. As igrejas no espaço público: rumo a uma teologia pública com enfoque na cidadania [2015]. Disponível em: $<$ https://www.academia.edu/19641413/ As_igrejas_no_espa $\% \mathrm{C} 3 \% \mathrm{~A} 7 \mathrm{o} \_\mathrm{p} \% \mathrm{C} 3 \% \mathrm{BAblico}$-_rumo_a_uma_teologia_p $\% \mathrm{C} 3 \% \mathrm{BAblica}$ _com_enfoque_na_cidadania>.

6 Sobre uma tipologia de teologias hegemônicas e contra-hegemônicas ver SANTOS, Boaventura de Sousa. Se Deus fosse um ativista dos direitos humanos. São Paulo: Cortez, 2014.

7 Sobre a recepção da diversidade como um dom ver TEIXEIRA, Faustino. Teologia e Pluralismo Religioso. São Bernardo do Campo: Nhanduti, 2012. 
Entre importantes figuras ligadas a essas questões se podem contar tanto religiosos quanto não religiosos. ${ }^{8}$

Historicamente a ideia de não violência pode ser originalmente ligada ao jainismo indiano já no século IX a.C., sistematizada por Mahavira três séculos mais tarde. Efetivamente, a não violência se destaca enquanto principal virtude jainista que incluía além da não violência física, a mental e a verbal, tornando-se base moral para a vida. Também o taoísmo valoriza a não violência, indicando, inclusive, que as armas não podem ser consideradas ferramentas de um bom governante. ${ }^{9}$

No contexto grego, apesar de não se utilizar o conceito de não violência, é possível detectar no julgamento e condenação de Sócrates a postura de não se entender como apropriada a resposta ao mal com o mal. A injustiça sofrida não deveria servir de justificativa para um ato violento. ${ }^{10}$

Também sem utilizar a terminologia de não violência, os seguidores de Jesus optaram por um pacifismo bastante consistente nos seus três primeiros séculos. Com a união do cristianismo ao império, seguiu-se a adoção da ideia de guerra justa, que deixa de ser acompanhada apenas no contexto da Reforma por alguns grupos como os anabatistas e os menonitas e no contexto católico pela crítica de Erasmo à própria noção de guerra justa. ${ }^{11}$

Expostos alguns elementos importantes das origens da ideia e da prática de não violência no Oriente e da relevância do pacifismo para a tradição cristã (apesar de sua profunda atuação bélica por séculos), torna-se possível olhar para os exemplos mais representativos na história recente da humanidade no que concerne à não violência, a saber, Gandhi e King.

Barry Gan identifica uma certa influência de Gandhi em King quando o segundo reconhece a filosofia de uma resistência não violenta como método apropriado na luta por liberdade feita por pessoas em situação de opressão. Essa filosofia é denominada satyagraha, a qual pode ser compreendida como um modo - não passivo - de se viver a vida na busca pela compreensão da verdade. Deus, na perspectiva de Gandhi, é identificado com a verdade. Um seguidor dessa filosofia, portanto, está comprometido com a verdade e se recusa a ferir qualquer pessoa nessa busca, mesmo que isso signifique que ele mesmo acabe sofrendo. ${ }^{12}$

Essa atitude foi assumida por King em suas lutas por direitos civis no contexto estadunidense. Com efeito, enquanto metodologia de protesto, o ativista valorizava a reunião de informações sobre a queixa a ser feita pelas pessoas afetadas; a disposição a

8 FIALA, Andrew. Introduction. In: FIALA, Andrew (Ed.). The Routledge Handbook of Pacifism and Nonviolence. New York; London: Routledge, 2018. p. 1-2.

9 CADY, Duane L. A history of the idea of pacifism and nonviolence: ancient to modern. In: FIALA (Ed.), 2018, p. 7-8.

${ }^{10}$ CADY, 2018, p. 9-10.

11 CADY, 2018, p. 10-12.

12 GAN, Barry L. The Gandhi-King tradition and satyagraha. In: FIALA (Ed.), 2018, p. 94. Nesse contexto cabe ressaltar que GAN (2018, p. 95), também identifica uma importante influência jainista em Gandhi, uma vez que os principais votos jainistas estão presentes na descrição que Gandhi faz daquilo que denomina de Satyagraha Ashram. 
uma autopurificação para que não se responda de modo violento à violência perpetrada; abertura ao diálogo e à negociação com a parte que causa aquilo que pode ser objetivo de queixa, bem como a necessidade de ação direta caso as negociações falhem. ${ }^{13}$

Há uma semelhança importante em Gandhi e King em sua busca pela verdade como um agarrar-se nessa verdade mesmo que se sofra por ela e em sua confiança na não violência como uma atitude com potencial de transformação da realidade. ${ }^{14}$

Assim, a prática da não violência em Gandhi e King não pode ser reduzida a uma interpretação de passividade. Pelo contrário, trata-se de uma disposição de sofrer por aquilo em que se acredita. Em ambos os casos, suas verdades estavam ligadas à luta por direitos e pelo reconhecimento da dignidade humana. Gandhi lutava pelos direitos das pessoas pobres indianas diante do imperialismo britânico e pelo reconhecimento da dignidade das pessoas consideradas intocáveis dentro da própria cultura indiana. King lutava pelos direitos dos afro-americanos em um contexto de segregação racial. Os dois pagaram com a vida em virtude de sua devoção à dignidade humana numa postura ativa de não violência e transformação social.

As teologias públicas dessas importantes figuras abrem as portas para uma reflexão acerca da relação entre religião e direitos humanos, bem como para uma atitude ética e prática para o diálogo inter-religioso. Diante disso, voltamos nossas atenções ao magistério pontifício para identificar de que modo a tradição católica, em sua representatividade oficial, se relacionou com uma ideia de origem jainista e que teve um hindu e um protestante batista como representantes de maior destaque, bem como investigar de que maneira o magistério pontifício conectou não violência e dignidade humana, algo que esteve no coração do ativismo social de Gandhi e King.

\section{Mapeamento das menções à não violência no magistério pontifício}

Este artigo é o primeiro resultado de uma pesquisa que mapeou todas as referências à não violência no magistério dos bispos de Roma. Para esse mapeamento, utilizamos a ferramenta de pesquisa avançada do Google, buscando pelos termos "nonviolenza", "non-violenza", "non violenza", "nonviolence", "non-violence", "non violence" nas páginas-mães de cada papa no site da Santa Sé. ${ }^{15}$ Os termos de busca, sempre entre aspas, abarcam as três possíveis grafias da expressão em italiano e em inglês/francês, as três línguas mais comuns no site da Santa Sé, no sentido de que quase todo o material disponível na página possui uma versão em italiano, mas um ou outro material pode ter apenas versões em inglês ou francês. Materiais disponíveis unicamente em uma quarta língua são bastante incomuns.

O resultado dessas buscas foi então manualmente selecionado, já que o mecanismo de pesquisa retornou páginas repetidas ou resultados que não correspondiam ao

13 GAN, 2018, p. 98.

${ }^{14}$ GAN, 2018, p. 99-100.

$15<$ http://www.vatican.va/content/paul-vi/>; <http://www.vatican.va/content/john-paul-i/ $>$; $<$ http://www. vatican.va/content/john-paul-ii/>; $<$ http://www.vatican.va/content/benedict-xvi/>; $<$ http://www.vatican. $\mathrm{va} /$ content/francesco/>. 
objetivo do mapeamento - por exemplo, quando um texto apresentava as palavras "não" e "violência" lado a lado sem o sentido da expressão "não violência". Catalogamos então todas as ocorrências que correspondiam ao objetivo do mapeamento, de maneira cronológica, utilizando preferencialmente a versão italiana ou, na falta dela, a inglesa.

Foram encontradas 76 ocorrências do termo "não violência" no magistério dos papas, que vão de dezembro de 1964 a fevereiro de 2020, mês em que concluímos o mapeamento: oito no magistério de Paulo VI (1963-1978), 32 no de João Paulo II (1978-2005), 20 no de Bento XVI (2005-2013) e 16 no de Francisco (2013-). Não foram encontradas ocorrências no curto pontificado de João Paulo I, papa entre 26 de agosto e 28 de setembro de 1978, nem no magistério dos dois papas que precederam imediatamente a Paulo VI - João XXIII (1958-1963) e Pio XII (1939-1958). Ficou claro que a não violência é uma temática que ganhou crescente atenção ao longo dos anos no magistério pontifício - uma tendência geral que o gráfico a seguir evidencia.

Gráfico 1. Menções à não violência nos textos do magistério pontifício a cada década (1964-2019)

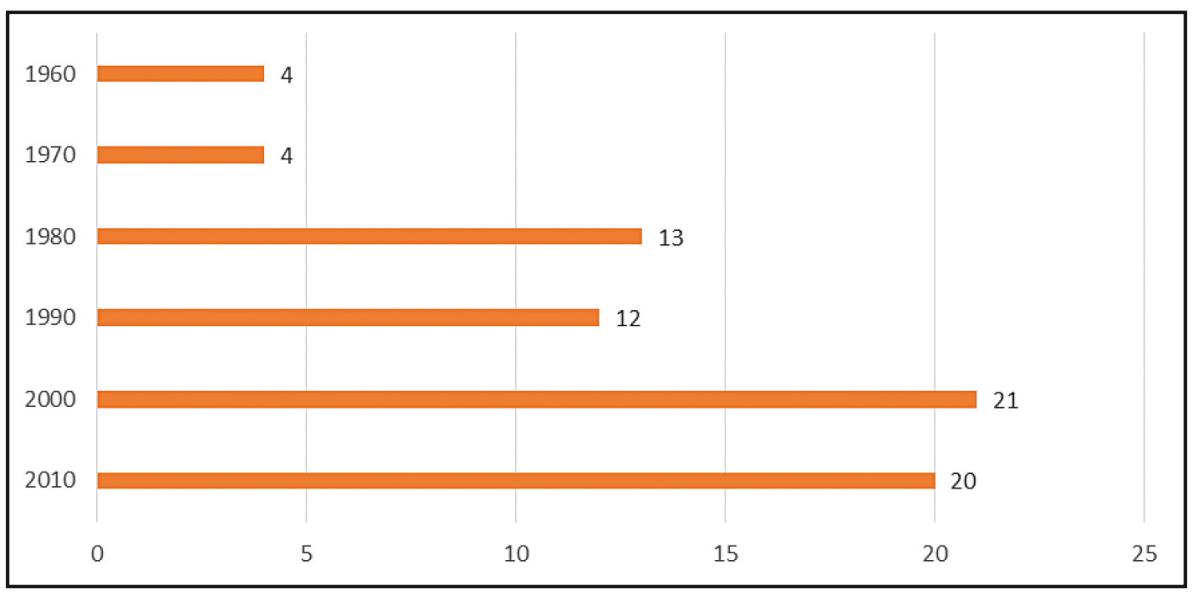

Para o estudo apresentado neste artigo, optamos por apresentar um recorte desse mapeamento, tendo como critério a temática da relação entre dignidade humana e não violência. Assim, selecionamos entre as 76 ocorrências aquelas que continham alguma menção direta ao tema da dignidade humana ou dos direitos humanos. Esse cruzamento resultou em 12 ocorrências - seis delas no magistério de João Paulo II, quatro no de Bento XVI e duas no de Francisco. Antes de nos determos sobre esse recorte, porém, é importante entender como a temática da não violência foi introduzida no magistério pontifício. 


\section{A introdução do tema da não violência no magistério dos papas}

Paulo VI foi o primeiro papa a utilizar a expressão "não violência" em seu magistério, o que ocorreu pela primeira vez em dezembro de 1964, durante sua viagem à Índia - a segunda de seu pontificado. Nessa ocasião, Paulo VI disse que a Índia "alimenta há muito tempo uma tradição de não violência" e que, também por isso, a sua "peregrinação" ao país tem "o valor de testemunho a favor da paz"16.

Entre as oito ocorrências do termo em seu magistério, três citam Gandhi. ${ }^{17}$ Somada à ocorrência mencionada no parágrafo anterior e a uma menção aos valores do budismo, ${ }^{18}$ são cinco as vezes em que Paulo VI fala de não violência em um contexto de alguma forma ligado ao diálogo inter-religioso. João Paulo II e Francisco ${ }^{19}$ também citaram Gandhi ao abordarem a não violência. João Paulo II, em visita ao seu memorial funerário, chegou a chamá-lo de "apóstolo da não violência"20.

As circunstâncias das menções de Paulo VI ao tema da não violência manifestam de modo claro que o princípio da não violência é algo que o magistério pontifício absorveu desde fora de si mesmo e de fora da própria tradição cristã, embora não tenha tardado a justificar o lugar de relevo desse princípio no próprio cristianismo. Foi também Paulo VI o primeiro papa a dar a entender que, em sua concepção, a não violência é inerente ao cristianismo, ao dizer que a igreja, "por seu princípio evangélico da não violência", não pode fazer sua a "linguagem desumana" da guerra. ${ }^{21}$

Décadas mais tarde, Bento XVI ${ }^{22}$ comentou essa origem extraeclesial, por assim dizer, do princípio da não violência, ao menos no contexto da contemporaneidade. Para ele, atualmente a moral teria se dividido em duas partes, uma delas redescoberta e empunhada pela "sociedade moderna" e outra proposta pela igreja, mas rejeitada pela mentalidade moderna. Bento XVI reconheceu assim que a não violência está inclusa nessa "outra parte da moral que, no anúncio da igreja nas últimas décadas e

16 Versão italiana: In questo Paese che da gran tempo alimenta una tradizione di non-violenza, Ci piace pensare che il Nostro pellegrinaggio assumerà anche il valore di testimonianza a favore della pace. (tradução nossa). Discurso aos componentes do corpo diplomático acreditado junto ao Governo Central Indiano. 03 de dezembro de 1964.

17 Carta ao presidente da Índia Varahagiri Venkata Giri, 22 de agosto de 1969; Mensagem para o IX Dia Mundial da Paz, $1^{\circ}$ de janeiro de 1976; Rádio-mensagem ao povo indiano em honra de Gandhi, 30 de janeiro de 1978.

18 Audiência geral, 5 de setembro de 1973.

19 Mensagem para o Dia Mundial da Paz, $1^{\circ}$ de janeiro de 2017.

20 Discurso durante visita ao Raj Ghat, $1^{\circ}$ de fevereiro de 1986.

21 Versão italiana: Oggi pur troppo si sono prodotte situazioni nel mondo, ed anche in Africa, di tale disagio e di tale avversione alla pacifica convivenza, che tornano ad avere triste corso le infauste parole di guerra, come espresse da una necessità ineluttabile. La Chiesa, proprio per l'indole sua, per il suo principio evangelico della "non violenza", non può fare proprio questo inumano linguaggio [...]. (tradução nossa). Discurso ao Parlamento da Uganda. $1^{\circ}$ de agosto de 1969.

22 Discurso no encontro com os bispos da Suiça. 09 de novembro de 2006. 
mesmo antes disso, talvez não tenha sido proposta suficientemente" e que foi "descoberta" pela "sociedade moderna", embora também pertença "à tradição da igreja". ${ }^{23}$

Francisco defendeu igualmente que a não violência "não é um patrimônio exclusivo da Igreja Católica, mas é próprio de muitas tradições religiosas" 24 . Tanto ele ${ }^{25}$ como João Paulo II $^{26}$ falaram da não violência como um valor moral universal, pertencente a diversas tradições religiosas, que encontraria o seu cumprimento em Jesus Cristo.

É oportuno reparar ainda que uma das ocorrências do termo "não violência" no magistério de Paulo VI se deu algumas semanas depois do assassinato de Martin Luther King Jr., sem dúvida uma das figuras em que o papa pensava ao falar de "exemplos magnânimos e sublimes de homens" que professaram "uma nobre e corajosa não violência" "27. Menos de quatro anos antes, em 18 de setembro de 1964, Paulo VI recebeu King em audiência no Vaticano - e um dos assuntos da conversa de 25 minutos foi justamente a recusa à violência como método de protesto. ${ }^{28}$ Em 07 de abril de 1968 , três dias depois da morte do ativista, o papa o recordou como "um profeta cristão pela integração racial" 29 . King chegou a ser mencionado explicitamente por João Paulo II ${ }^{30}$ e Francisco ${ }^{31}$ em ocasiões em que falaram de não violência.

\section{Dignidade humana e não violência no magistério pontifício}

A primeira vez em que o magistério dos papas relacionou a não violência com a dignidade humana se deu justamente em torno de uma menção a King, durante uma visita de João Paulo II aos Estados Unidos. Nessa ocasião, o papa definiu a não violência como "a única abordagem verdadeiramente efetiva para assegurar e salvaguardar

${ }^{23}$ Versão italiana: Su questo ho riflettuto - ci rifletto già da molto tempo - e vedo sempre più chiaramente che, nella nostra epoca, la morale si è come divisa in due parti. La società moderna non è semplicemente senza morale, ma ha, per cosi dire, "scoperto" e rivendica un'altra parte della morale che, nell 'annuncio della Chiesa negli ultimi decenni e anche di più, forse non è stata abbastanza proposta. Sono i grandi temi della pace, della non violenza, della giustizia per tutti, della sollecitudine per i poveri e del rispetto della creazione. [...] E sono davvero grandi temi morali, che appartengono del resto anche alla tradizione della Chiesa. [...]. L'altra parte della morale, che non di rado viene colta in modo assai controverso dalla politica, riguarda la vita. Fa parte di essa l'impegno per la vita, dalla concezione fino alla morte, cioè la sua difesa contro l'aborto, contro l'eutanasia, contro la manipolazione e contro l'auto-legittimazione dell'uomo a disporre della vita. [...] In questo contesto si pone poi anche la morale del matrimonio e della famiglia. (tradução nossa).

${ }^{24}$ Mensagem para o Dia Mundial da Paz. $1^{\circ}$ de janeiro de 2017.

${ }_{25}$ Discurso por ocasião da apresentação das cartas credenciais dos embaixadores da Suécia, Fiji, Moldávia, Maurício, Tunísia e Burundi. 15 de dezembro de 2016.

${ }^{26}$ Exortação apostólica pós-sinodal Ecclesia in Asia. 06 de novembro de 1999, n. 14.

27 Versão italiana: Dopo l'esaltazione di esempi come magnanimi e sublimi di uomini, che hanno promosso movimenti ideali e sociali di grande importanza e con grande efficacia, professando una nobile e coraggiosa «non-violenza», ecco che, in certi ambienti, la violenza torna di moda. (tradução nossa). Discurso ao Colégio Cardinalício na Solenidade de São João Batista. 24 de junho de 1968.

28 DR. KING GETS PAPAL PLEDGE. New York Herald Tribune, European Edition, Sept. 19, 1964.

29 Angelus. 07 de abril de 1968.

30 Discurso no encontro com a comunidade católica negra de New Orleans. 12 de novembro de 1987.

31 Mensagem para o Dia Mundial da Paz. $1^{\circ}$ de janeiro de 2017. 
a dignidade humana", destacando nisso o exemplo de King, que desempenhou um "papel providencial" na luta pelos direitos civis - uma "ação libertadora" de Deus que é "sinal e expressão do mistério pascal de Cristo"32.

João Paulo II considerava, pois, que qualquer forma de violência vilipendia a dignidade humana, de tal forma que, em meio a confrontos de toda ordem, apenas o caminho da não violência protege essa dignidade. Um ano depois desse discurso, durante sua visita ao Lesoto, ele reforçou essa concepção, definindo a opção pela não violência como "uma escolha corajosa de amor, uma escolha que implica a tutela efetiva dos direitos do homem e um compromisso firme pela justiça e por um desenvolvimento harmonioso". Na época, o país vivia um período conturbado de sua história, tendo sofrido um golpe militar dois anos antes, em 1986. Nesse contexto, o papa fez questão de deixar claro, como em outras ocasiões, ${ }^{33}$ que a não violência não é "uma aceitação passiva de situações de injustiça": o "seu objetivo é buscar ativamente "não se deixar vencer pelo mal, mas vencer o mal com o bem' ( $\mathrm{Rm} 12,21)^{\prime 334}$.

Uma outra circunstância histórica está atrelada a uma menção que João Paulo II fez à ligação entre não violência e direitos humanos, embora seja en passant e sem uma maior elaboração da relação entre esses conceitos. Em um discurso ao novo embaixador do Panamá junto à Santa Sé em dezembro de 1990, o papa recordou a invasão dos Estados Unidos ao país, ocorrida um ano antes, assegurando que naquele contexto a igreja defendeu "os direitos humanos e as liberdades públicas" e apoiou "a democracia e a não violência", o que "manteve a esperança e o ânimo dos cidadãos" e "assentou as bases do processo de reconstrução social". João Paulo II afirmou ainda que "a igreja, como a defensora da verdade sobre a pessoa humana, não pode permanecer indiferente a eventos ou circunstâncias que, individual ou coletivamente, ameacem a dignidade humana ou os direitos humanos" ${ }^{\prime 35}$.

32 Versão inglesa: Today as we recall who with Christian vision opted for non-violence as the only truly effective approach for ensuring and safeguarding human dignity, we cannot but think of the Reverend Dr Martin Luther King, Jr, and of the providential role he played in contributing to the rightful human betterment of black Americans and therefore to the improvement of American society itself. My dear brothers and sisters of the black community: it is the hour to give thanks to God for his liberating action in your history and in your lives. This liberating action is a sign and expression of Christ's Paschal Mystery, which in every age is effective in helping God's people to pass from bondage into their glorious vocation of full Christian freedom. (tradução nossa). Discurso no encontro com a comunidade católica negra de New Orleans. 12 de novembro de 1987.

${ }_{33}$ Por exemplo, no Discurso aos juristas católicos. 06 de dezembro de 1980.

${ }^{34}$ Versão italiana: Qualcuno potrà dirvi che la scelta della non violenza non è in definitiva altro che una passiva accettazione di situazioni d'ingiustizia. Potrà sostenere che è da vili non usare violenza contro ciò che è ingiusto, o rifiutare di difendere con violenza gli oppressi. Ma nulla potrebbe essere più lontano dalla verità. Non vi è nulla di passivo nella non violenza, quando è una scelta dettata dall'amore. Non ha nulla a che vedere con l'indifferenza. Il suo obiettivo è di cercare attivamente di "non lasciarsi vincere dal male, ma vincere con il bene il male", come c'invita a fare san Paolo (Rm 12, 21). Scegliere la non-violenza significa fare una scelta coraggiosa di amore, una scelta che implica la tutela effettiva dei diritti dell'uomo e un fermo impegno per la giustizia e per uno sviluppo armonico. (tradução nossa). Discurso no encontro com jovens em Maseru. 15 de setembro de 1988.

35 Versão inglesa: During those crucial days, as you wished to mention, the Church with her bishops in the forefront did not relax her involvement in the works of justice and mercy, in defence of human rights and 
As outras duas ocorrências de alguma relação entre a dignidade humana e a não violência em seu magistério se dão no contexto do diálogo inter-religioso. Em 1994, falando aos bispos do Sri Lanka, João Paulo II elencou tanto "a dignidade inviolável de cada vida humana" como a não violência entre os "valores comuns" entre o budismo e o cristianismo. ${ }^{36}$ Cinco meses depois, em visita ao país, aprofundou a relação entre esses elementos ao dizer aos líderes religiosos srilanqueses que "os princípios da misericórdia e da não violência", presentes nas tradições religiosas ali existentes, "serão uma fonte de inspiração para os habitantes do Sri Lanka em seus esforços para construir uma paz que seja duradoura por ser baseada na justiça e no respeito por cada ser humano"37. Para João Paulo II, portanto, uma paz duradoura precisa estar fundamentada no reconhecimento da dignidade de cada pessoa, o que não se dá fora de uma abordagem de não violência - e o diálogo entre as tradições religiosas é um elemento particularmente relevante nesse processo, na medida em que ressalta os valores comuns e educa para eles.

Em três das quatro vezes em que teceu alguma relação entre a dignidade humana e a não violência, Bento XVI insistiu em uma mesma ideia. Já vimos os pressupostos dessa tese, isto é, as duas partes em que a moral teria se dividido nos dias atuais. A não violência estaria na primeira parte, descoberta pela sociedade moderna, enquanto a defesa da vida humana da concepção à morte natural estaria na segunda, proposta pela igreja, mas dificilmente aceita. O que Bento XVI defendeu é que essas duas partes não podem ser separadas, como afirmou em 2006:

Somente se se respeita a vida humana, desde a concepção até à morte, também a ética da paz é possível e credível; somente então a não violência pode expressar-se em todas as direções, só assim acolhemos verdadeiramente a criação e somente então é possível alcançar a verdadeira justiça ${ }^{38}$.

of civil freedoms. That, along with her support for democracy and non-violence, not only maintained the hope and the courage of the citizens, but also set the basis for the process of social reconstruction. The Church as the defender of the truth about the human person cannot remain indifferent to events or circumstances which, on an individual or collective level, threaten human dignity or human rights. (tradução nossa). Discurso ao Sr. Lionel Rudolph Stempel, novo embaixador do Panamá junto à Santa Sé. 13 de dezembro de 1990.

${ }^{36}$ Versão italiana: Il dialogo interreligioso nello Sri Lanka, in particolare quello con la comunità maggioritaria dei buddisti può basarsi sul riconoscimento di valori comuni quali l'inalienabile dignità di ogni vita umana, l'inestimabile valore della famiglia, il rispetto per la vita virtuosa, la non violenza e il dimenticare se stessi nel soddisfare i bisogni altrui. (tradução nossa). Discurso aos bispos do Sri Lanka em visita ad limina apostolorum. 24 de agosto de 1994.

37 Versão italiana: [S]ono certo del fatto che i principi di misericordia e di non violenza, presenti nelle vostre tradizioni, saranno una fonte di ispirazione per gli abitanti dello Sri Lanka nei loro sforzi per costruire una pace che sia duratura perché basata sulla giustizia e sul rispetto per ogni essere umano. (tradução nossa). Discurso no encontro com líderes de outras religiões em Colombo. 21 de janeiro de 1995.

38 Versão italiana: Solo se si rispetta la vita umana dalla concezione fino alla morte, è possibile e credibile anche l'etica della pace; solo allora la non violenza può esprimersi in ogni direzione, solo allora accogliamo veramente la creazione e solo allora si può giungere alla vera giustizia. (tradução nossa). Discurso no encontro com os bispos da Suiça. 09 de novembro de 2006. 
No ano seguinte, ele retomou essa tese, dizendo que os temas “da paz, da não violência, da justiça e do respeito pela criação", por "grandes e vitais" que sejam, "não conferem por si mesmos a dignidade ao homem". Segundo Bento XVI, "a dimensão primária da moralidade vem da dignidade inata da vida humana - do momento da concepção até a morte natural -, uma dignidade conferida pelo próprio Deus" ${ }^{39}$.

Ele ressaltou uma terceira vez essa ideia em 2008, em sua viagem à Austrália, ao afirmar que "as preocupações pela não violência, pelo progresso sustentável, pela justiça e pela paz e pelo cuidado do nosso ambiente são de importância vital para a humanidade", mas não podem ser compreendidas "prescindindo de uma reflexão profunda sobre a dignidade inata de cada vida humana da concepção até à morte natural, uma dignidade que é conferida pelo próprio Deus e, por isso, inviolável"40.

Finalmente, em 2011, Bento XVI tratou da relação entre a não violência e a dignidade humana sem se preocupar com a ressalva que caracterizou suas proposições anteriores. Nessa ocasião, de tons mais positivos - ainda que Bento XVI nunca tenha posto em dúvida o valor eminente que entende que a não violência tem para a fé cristã ${ }^{41}$-, ele disse que "a regra do respeito e da não violência - isto é, a força da verdade contra todo abuso - é a que pode assegurar um futuro digno do homem"42.

O papa Francisco é o autor daquele que pode ser considerado o principal texto de todo o magistério pontifício a respeito do tema - sua mensagem para o Dia Mundial da Paz de 2017, em que o termo "não violência" aparece 20 vezes, sem contar o título. Nesse texto, ele aborda a relação entre a dignidade humana e a não violência já no primeiro parágrafo. Ali, o papa afirmou orar "para que a imagem e a semelhança de Deus em cada pessoa nos permitam reconhecermo-nos uns aos outros como dons sagrados dotados de uma dignidade imensa". Esse reconhecimento da dignidade humana como algo de precioso é o que fundamenta a "não violência ativa" como "estilo de vida". ${ }^{43}$

Poucos dias depois da data oficial da mensagem, Francisco recomendou-a em um discurso a diplomatas, apontando que o objetivo do texto é "recordar antes de tudo

39 Versão inglesa: The great and vital moral themes of peace, non-violence, justice, and respect for creation do not in themselves confer dignity on man. The primary dimension of morality stems from the innate dignity of human life) from the moment of conception to natural death) a dignity conferred by God himself. (tradução nossa). Discurso ao Sr. Noel Fahey, novo embaixador da Irlanda junto à Santa Sé. 15 de setembro de 2007.

${ }^{40}$ Versão italiana: Le preoccupazioni per la non violenza, lo sviluppo sostenibile, la giustizia e la pace, la cura del nostro ambiente sono di vitale importanza per l'umanità. Tutto ciò non può però essere compreso a prescindere da una profonda riflessione sull 'innata dignità di ogni vita umana dal concepimento fino alla morte naturale, una dignità che è conferita da Dio stesso e perciò inviolabile. (tradução nossa). Discurso na festa de acolhida da XXIII Jornada Mundial da Juventude em Sydney. 17 de julho de 2008.

${ }^{41}$ Por exemplo, em seu Ângelus de 18 de fevereiro de 2007.

${ }^{42}$ Versão italiana: Ma soprattutto nei rapporti umani, interpersonali, sociali, la regola del rispetto e della non violenza, cioè la forza della verità contro ogni sopruso, è quella che può assicurare un futuro degno dell'uomo. (tradução nossa). Angelus. 03 de julho de 2011.

${ }^{43}$ Versão italiana: Auguro pace ad ogni uomo, donna, bambino e bambina e prego affinché l'immagine e la somiglianza di Dio in ogni persona ci consentano di riconoscerci a vicenda come doni sacri dotati di una dignità immensa. Soprattutto nelle situazioni di conflitto, rispettiamo questa "dignità più profonda" [Evangelii gaudim, n. 228] e facciamo della nonviolenza attiva il nostro stile di vita. (tradução nossa). Mensagem para o Dia Mundial da Paz. $1^{\circ}$ de janeiro de 2017. 
que a não violência é um estilo político, baseado no primado do direito e da dignidade de toda pessoa" ${ }^{\text {44 }}$. Assim, o papa ressaltou a ligação entre a dignidade humana e a não violência em uma linguagem ligeiramente diferente da de seu predecessor. Os termos que Bento XVI usa podem ser utilizados para deslegitimar a reivindicação de não violência quando ela parte de uma pessoa ou um grupo que não concorde com a definição "da concepção à morte natural" para abarcar a amplitude do reconhecimento da dignidade humana. Os termos de Francisco, como os de João Paulo II, não têm esse tom de ressalva e enfatizam a lógica inversa: se reconhecemos a dignidade humana, então temos a não violência por estilo de vida.

\section{Considerações finais}

É relevante o fato de que uma prática de origem jainista e que possui como principais referenciais um hindu e um protestante ocupe espaço no magistério pontifício. Há aqui importantes contribuições para uma teologia pública, para o ecumenismo, para o diálogo inter-religioso e para a promoção cristã dos direitos humanos.

A não violência como método de protesto e enquanto ideia-força pública conjuga teologia pública e direitos humanos. Pensa-se no reconhecimento de injustiças que querem ser combatidas com base em referenciais teológicos com capacidade de incidência pública e transformação social. A disposição revolucionária de uma não violência ativa lança desafios bem concretos aos discursos teológicos que defendem a dignidade humana para que intervenham de modo prático lá onde as injustiças são identificadas. Ademais, a não violência no magistério pontifício, em King, em Gandhi e no jainismo desvela potencial inter-religioso. Ao se assumir a não violência como algo a ser colocado em prática, a reunião de igrejas e religiões em favor de uma causa humana possui caráter público de luta por direitos.

Em resumo, nota-se a força de sentido da não violência em sua possibilidade de contribuição a uma ética pública, como elemento de destaque no diálogo inter-religioso e como resistência às formas religiosas de expressão que se caracterizam justamente pelo ódio e pela violência.

\section{Referências}

BENTO XVI. Ângelus. 18 de fevereiro de 2007. Disponível em: <http://www.vatican.va/content/ benedict-xvi/it/angelus/2007/documents/hf_ben-xvi_ang_20070218.html>.Acesso em: 28 fev. 2020. BENTO XVI. Angelus. 03 de julho de 2011. Disponível em: <http://www.vatican.va/content/benedictxvi/it/angelus/2011/documents/hf_ben-xvi_ang_20110703.html>. Acesso em: 28 fev. 2020.

BENTO XVI. Discurso ao Sr. Noel Făhey, novo embaixador da Irlanda junto à Santa Sé. 15 de setembro de 2007. Disponível em: <http://www.vatican.va/content/benedict-xvi/en/

44 Versão italiana: Proprio a tale principio ho voluto dedicare il Messaggio per la Giornata Mondiale della Pace 2017 [...] per richiamare anzitutto come la nonviolenza sia uno stile politico, basato sul primato del diritto e della dignità di ogni persona. (tradução nossa). Discurso por ocasião dos cumprimentos ao corpo diplomático acreditado junto à Santa Sé. 09 de janeiro de 2017. 
speeches/2007/september/documents/hf_ben-xvi_spe_20070915_ambassador-ireland.html>. Acesso em: 28 fev. 2020.

BENTO XVI. Discurso na festa de acolhida da XXIII Jornada Mundial da Juventude em Sydney. 17 de julho de 2008. Disponível em: <http://www.vatican.va/content/benedict-xvi/it/speeches/2008/ july/documents/hf_ben-xvi_spe_20080717_barangaroo.html >. Acesso em: 28 fev. 2020.

BENTO XVI. Discurso no encontro com os bispos da Suiça. 09 de novembro de 2006. Disponível em: <http://www.vatican.va/content/benedict-xvi/it/speeches/2006/november/documents/ hf_ben-xvi_spe_20061109_concl-swiss-bishops.html>. Acesso em: 28 fev. 2020.

CADY, Duane L. A history of the idea of pacifism and nonviolence: ancient to modern. In: FIALA, Andrew (Ed.). The Routledge Handbook of Pacifism and Nonviolence. New York; London: Routledge, 2018. p. 7-14.

DR. KING GETS PAPAL PLEDGE. New York Herald Tribune, European Edition, Sept. 19, 1964. Disponível em: <https://iht-retrospective.blogs.nytimes.com/2014/09/18/1964-dr-kinggets-papal-pledge/>. Acesso em: 28 fev. 2020.

FIALA, Andrew. Introduction. In: FIALA, Andrew (Ed.). The Routledge Handbook of Pacifism and Nonviolence. New York; London: Routledge, 2018. p. 1-4.

FRANCISCO [Papa]. Discurso por ocasião da apresentação das cartas credenciais dos embaixadores da Suécia, Fiji, Moldávia, Maurício, Tunísia e Burundi. 15 de dezembro de 2016. Disponível em: <http://www.vatican.va/content/francesco/it/speeches/2016/december/documents/ papa-francesco_20161215_ambasciatori.html>. Acesso em: 28 fev. 2020.

FRANCISCO [Papa]. Discurso por ocasião dos cumprimentos ao corpo diplomático acreditado junto à Santa Sé. 09 de janeiro de 2017. Disponível em: <http://www.vatican.va/content/ francesco/it/speeches/2017/january/documents/papa-francesco_20170109_corpo-diplomatico. html>. Acesso em: 28 fev. 2020.

FRANCISCO [Papa]. Mensagem para o Dia Mundial da Paz. $1^{\circ}$ de janeiro de 2017. Disponível em: <http://www.vatican.va/content/francesco/it/messages/peace/documents/papafrancesco_20161208_messaggio-l-giornata-mondiale-pace-2017.html >. Acesso em: 28 fev. 2020. GAN, Barry L. The Gandhi-King tradition and satyagraha. In: FIALA, Andrew (Ed.). The Routledge Handbook of Pacifism and Nonviolence. New York; London: Routledge, 2018. p. 93-101. JOÃO PAULO II. Discurso ao Sr. Lionel Rudolph Stempel, novo embaixador do Panamá junto à Santa Sé. 13 de dezembro de 1990. Disponível em: <http://www.vatican.va/content/john-paulii/en/speeches/1990/december/documents/hf-jp-ii_spe_19901213_amb-panama.html>. Acesso em: 28 fev. 2020.

JOÃO PAULO II. Discurso aos bispos do Sri Lanka em visita ad limina apostolorum. 24 de agosto de 1994. Disponível em: <http://www.vatican.va/content/john-paul-ii/it/speeches/1996/ august/documents/hf_jp-ii_spe_19960824_sri-lanka-ad-limina.html>. Acesso em: 28 fev. 2020. JOÃO PAULO II. Discurso aos juristas católicos. 06 de dezembro de 1980. Disponível em: $<$ http://www.vatican.va/content/john-paul-ii/it/speeches/1980/december/documents/hf_jpii_spe_19801206_giuristi-cattolici.html >. Acesso em: 28 fev. 2020.

JÕ̃̃O PAULO II. Discurso durante visita ao Raj Ghat. $1^{\circ}$ de fevereiro de 1986. Disponível em: <http://www.vatican.va/content/john-paul-ii/it/speeches/1986/february/documents/hf_jpii_spe_19860201_raj-ghat.html>. Acesso em: 28 fev. 2020.

JŌ̃̃O PAULO II. Discurso no encontro com a comunidade católica negra de New Orleans. 12 de novembro de 1987. Disponível em: <http://www.vatican.va/content/john-paul-ii/en/ speeches/1987/september/documents/hf_jp-ii_spe_19870912_cattolici-new-orleans.pdf $>$. Acesso em: 28 fev. 2020. 
JOÃO PAULO II. Discurso no encontro com jovens em Maseru. 15 de setembro de 1988. Disponível em: <http://www.vatican.va/content/john-paul-ii/it/speeches/1988/september/documents/ hf_jp-ii_spe_19880915_giovani-maseru.html>. Acesso em: 28 fev. 2020.

JOÃO PAULO II. Discurso no encontro com líderes de outras religioes em Colombo. 21 de janeiro de 1995. Disponível em: <http:/www.vatican.va/content/john-paul-ii/it/speeches/1995/january/ documents/hf_jp-ii_spe_19950121_altre-religioni-colombo.html >. Acesso em: 28 fev. 2020.

JOÃO PAULO II. Exortação apostólica pós-sinodal Ecclesia in Asia. 06 de novembro de 1999. Disponível em: <http://www.vatican.va/content/john-paul-ii/it/apost_exhortations/documents/ hf_jp-ii_exh_06111999_ecclesia-in-asia.html>. Acesso em: 28 fev. 2020.

PAULO VI. ÂAngelus. 07 de abril de 1968. Disponível em: < http://www.vatican.va/content/paulvi/it/angelus/1968/documents/hf_p-vi_ang_19680407.html>. Acesso em: 28 fev. 2020.

PAULO VI. Audiência geral. 05 de setembro de 1973. Disponível em: <http://www.vatican.va/ content/paul-vi/it/audiences/1973/documents/hf_p-vi_aud_19730905.html >. Acesso em: 28 fev. 2020. PAULO VI. Carta ao presidente da Índia Varahagiri Venkata Giri. 22 de agosto de 1969. Disponível em: <http://www.vatican.va/content/paul-vi/en/letters/1969/documents/hf_pvi_let_19690822_varahagiri-venkah-giri.html>. Acesso em: 28 fev. 2020.

PĀULO VI. Discurso ao Colégio Cardinalício na Solenidade de São João Batista. 24 de junho de 1968. Disponível em: <http://www.vatican.va/content/paul-vi/it/speeches/1968/june/documents/ hf_p-vi_spe_19680624_sacro-collegio.html>. Acesso em: 28 fev. 2020.

PAULO VI. Discurso ao Parlamento da Uganda. $1^{\text {o }}$ de agosto de 1969. Disponível em: <http:// www.vatican.va/content/paul-vi/it/speeches/1969/august/documents/hf_p-vi_spe_19690801_ parlamento-uganda.html>. Acesso em: 28 fev. 2020.

PAULO VI. Discurso aos componentes do corpo diplomático acreditado junto ao Governo Central Indiano. 03 de dezembro de 1964. Disponível em: <http://www.vatican.va/content/ paul-vi/it/speeches/1964/documents/hf_p-vi_spe_19641203_corps-diplomatique.html >.Acesso em: 28 fev. 2020.

PAULO VI. Mensagem para o IX Dia Mundial da Paz. $1^{\circ}$ de janeiro de 1976. Disponível em: $<$ http://www.vatican.va/content/paul-vi/it/messages/peace/documents/hf_p-vi_mes_19751018_ ix-world-day-for-peace.html>. Acesso em: 28 fev. 2020.

PAULO VI. Rádio-mensagem ao povo indiano em honra de Gandhi. 30 de janeiro de 1978. Disponível em: <http://www.vatican.va/content/paul-vi/en/speeches/1978/january/documents/ hf_p-vi_spe_19780131_popolo-indiano.html>. Acesso em: 28 fev. 2020.

SANTOS, Boaventura de Sousa. Se Deus fosse um ativista dos direitos humanos. São Paulo: Cortez, 2014.

SINNER, Rudolf von. As igrejas no espaço público: rumo a uma teologia pública com enfoque na cidadania [2015]. Disponível em: <https://www.academia.edu/19641413/As_igrejas_no_ espa\%C3\%A7o_p $\%$ C3\%BAblico_-_rumo_a_uma_teologia_p $\% \mathrm{C} 3 \% \mathrm{BAblica}$ _com_enfoque na_cidadania $>$. Acesso em: 28 fev. 2020.

TEIXEIRA, Faustino. Teologia e Pluralismo Religioso. São Bernardo do Campo: Nhanduti, 2012. 